\title{
Predicted 10-year risk of cardiovascular disease in the Islamic Republic of Iran and the body mass index paradox
}

Mohammad Hassan Emamian, ${ }^{1}$ Hassan Hashemi ${ }^{2}$ and Akbar Fotouhi ${ }^{3}$

${ }^{1}$ Center for Health Related Social and Behavioral Sciences Research, Shahroud University of Medical Sciences, Shahroud, Islamic Republic of Iran. ${ }^{2}$ Noor Ophthalmology Research Center, Noor Eye Hospital, Tehran, Islamic Republic of Iran. ${ }^{3}$ Department of Epidemiology and Biostatistics, School of Public Health, Tehran University of Medical Sciences, Tehran, Islamic Republic of Iran. (Correspondence to: Akbar Fotouhi: afotouhi@tums.ac.ir).

\begin{abstract}
Background: Assessment of the risk of cardiovascular disease is essential for disease prevention in every region.

Aims: This study aimed to investigate the 10-year risk of cardiovascular disease and its determinants in an adult population in Shahroud, Islamic Republic of Iran.

Methods: A total of 4737 people aged 45-69 years were evaluated. The 10-year risk of cardiovascular disease was calculated using the Framingham risk scoring method. Cardiovascular disease risk is reported as per cent risk and 95\% confidence intervals (CI). Factors affecting the risk of cardiovascular disease were assessed using multiple beta regression analysis.

Results: The mean age of the participants was 55.9 years; $41 \%$ were males. The mean 10 -year risk of developing cardiovascular disease was $16.4 \%$ (95\% CI: $16.0-16.8 \%$ ); $28.3 \%$ of the participants had a risk of more than $20 \%$ ( $47.8 \%$ of the men and $14.9 \%$ of the women). Age, diabetes, smoking (only in men), high blood pressure, triglycerides (only in women), waist circumference, total cholesterol and high-density lipoprotein cholesterol were significantly associated with cardiovascular disease risk. In men, there was a non-significant increase in risk with higher body mass index up to body mass index 39.9 $\mathrm{kg} / \mathrm{m}^{2}$; however, the risk decreased by $4.4 \%$ at body mass index $\geq 40 \mathrm{~kg} / \mathrm{m}^{2}(P=0.18)$.
\end{abstract}

Conclusions: The cardiovascular disease risk was very high, especially in men. Effective interventions should be implemented to reduce risk factors for cardiovascular disease. Longitudinal studies are recommended to investigate the effect of body mass index on the risk of cardiovascular disease.

Keywords: cardiovascular diseases, risk factors, body mass index, Iran

Citation: Emamian MH; Hashemi H; Fotouhi A. Predicted 10-year risk of cardiovascular disease in the Islamic Republic of Iran and the body mass index paradox. East Mediterr Health J. 2020;26(12):1465-1472. https://doi.org/10.26719/emhj.20.012

Received: 14/12/18; accepted: 25/06/19

Copyright (c) World Health Organization (WHO) 2020. Some rights reserved. This work is available under the CC BY-NC-SA 3.0 IGO license (https:// creativecommons.org/licenses/by-nc-sa/3.o/igo).

\section{Introduction}

Cardiovascular diseases (CVDs) with about 422.7 million cases and 17.9 million deaths a year (31\% of all deaths) are the leading cause of death in the world $(1,2)$. About three quarters of these deaths occur in low- and middle-income countries. However, most of these deaths could be prevented with the avoidance of certain risk factors, such as smoking, unhealthy diet, obesity, sedentary lifestyle and alcohol use. People with CVD or those with increased risk of the diseases require early diagnosis and therapy (2). Although the CVD deaths increased by $21 \%$ between 2007 to 2017, the age-adjusted death rates declined during this period in all high-income and some middle-income countries $(1,3)$. The Islamic Republic of Iran has one of the highest age-standardized prevalence rates of CVD (> 9000 cases per 100000 people) (1) and a high CVD mortality rate (4). By 2025, the burden of the CVD in the country will be more than double the rate in 2005 (5).

Since 2001, several guidelines have calculated and predicted the risk of CVD (6). Such calculations are important in guiding primary and secondary prevention of CVDs (6). By identifying CVD risk, in addition to raising awareness, appropriate interventions can be designed and implemented at the community level (primary prevention). In addition, medications such as lipidlowering drugs may also be prescribed at the individual level (secondary prevention).

The Framingham risk score is one of the most widely used risk scores with a good ability to separate high-risk individuals from others (discrimination) and to predict the risk of CVD (calibration) (6). This score has been used in various countries as a useful tool to predict the CVD risks (6-9). A cohort study with long-term follow-up confirmed the correctness of the predictive power of the Framingham risk score (10).

A few studies have investigated the risk of CVD in the Islamic Republic of Iran (7,11-17), but the results have varied because of differences in the objectives and methods; therefore, it is difficult to draw conclusions about the risk of CVD in the country. The aim of our study was to evaluate the risk of CVD in a population-based study using the Framingham risk score and to identify factors associated with CVD risk in Shahroud, Islamic Republic of Iran. 


\section{Methods}

\section{Study population}

Our study is based on data from the second phase of the Shahroud Eye Cohort Study, done in Shahroud, northern Islamic Republic of Iran. Details of the study methodology have already been described (18) but here we provide a summary of the methodology of the Shahroud Eye Cohort Study.

In 2009,6311 people in the 300 clusters from nine strata of Shahroud city were selected using stratified cluster random sampling. The strata were the nine health care centres in the city and the number of clusters was calculated proportionate to the population served by the centre. We selected 20 people aged 40-64 years from each cluster for the study. The selected people were interviewed and invited to have an ophthalmologic examination. Demographic characteristics, employment status, medical and ophthalmic history were recorded for participants. The second phase of the study began in 2014 and the participants of the first phase were invited to take part. In the first phase, 5190 people aged 40-64 years participated in the study (82.2\% response rate). In the second phase 4737 of the participants of the first phase (91.3\%) agreed to participate. In the second, phase 5 years later, the ages of the participants ranged from 45-69 years.

\section{Measurements}

In both phases, weight was determined using a portable digital scale (in kilograms with an accuracy of $0.1 \mathrm{~kg}$ ). Height was measured using non-elastic tape measure in standing position and without shoes (in metres). Body mass index (BMI) was calculated as weight (in kilograms) divided by the square of height (in metres). Waist circumference was measured in the horizontal plane midway between lowest rib and the iliac crest to the nearest 0.1 $\mathrm{cm}$ using a non-elastic tape measure.

A trained nurse measured blood pressure in the right hand in a sitting position after resting for 5 minutes using an electronic sphygmomanometer. Blood pressure was measured two consecutive times with an interval of 3 minutes. After the two measurements, if a difference between values was more than $10 \mathrm{mmHg}$ in systolic blood pressure or $5 \mathrm{mmHg}$ in diastolic blood pressure, the measurement was repeated for a third time and the two measurements closer together were used. Mean systolic and diastolic blood pressure of the two measurements was calculated. People with high blood pressure were those with a mean systolic blood pressure $\geq 140 \mathrm{mmHg}$ or a mean diastolic blood pressure of $\geq 90 \mathrm{mmHg}$ or who were taking blood pressure medications.

Participants who had smoked cigarettes, the water pipe or pipe for most days of the week over at least 6 months were considered as smokers.

\section{Blood tests}

Fasting plasma glucose, serum triglycerides, total cholesterol, high-density lipoprotein (HDL) cholesterol and gly- cosylated haemoglobin (HbAlc) were measured.

All laboratory tests were performed using the Alpha Classic-At Plus autoanalyser (Tajhizat Sanjesh Company, Islamic Republic of Iran) after 10-12 hours fasting. The kits used were manufactured by Pars-Azmoon Company and were within the expiry date. Quality control of the autoanalyser was done daily before the start of the measurements.

A participant was considered to have diabetes if he/ she: had fasting plasma glucose $\geq 126 \mathrm{mg} / \mathrm{dL}$ and/or $\mathrm{HbA1c} \geq 6.5 \%$ and/or was taking medicines to lower blood glucose.

\section{Statistical analysis}

Variables including age, sex, systolic blood pressure, total cholesterol, HDL cholesterol, taking blood pressure medicines, smoking and diabetes were used to calculate the 10-year risk of CVDs as percentage according to the Framingham risk score (19). The participants with 10-year risk more than $20 \%$ were identified as a high-risk group.

Estimated mean CVD risk and the prevalence of risk over $20 \%$ were compared by age and sex with 95\% confidence intervals (CI). The association of CVD risk with the independent variables was investigated using multiple beta regression models. Considering the statistical interactions between sex and BMI, and also between age and triglycerides, the beta regression analyses were performed for men and women separately. The significance level for all tests was 0.05 and the effect of cluster sampling was considered in the calculation of CIs.

\section{Ethical considerations}

The study protocol was reviewed and approved by the Ethics Committee of Shahroud University of Medical Sciences in both phases of the Shahroud Eye Cohort Study.

After explaining the purpose of the project, written informed consent was obtained from each participant. Illiterate participants signed the consent form with their fingerprint after it was explained to them.

\section{Results}

Of the 4737 people who participated in the second phase of study, data to calculate the CVD risk were available for 4661 people aged between 45 and 69 years, including 1907 men (40.9\%) and 2754 (59.1\%) women. The mean age (standard deviation) was 55.9 (6.2) years. The mean CVD risk per cent was $16.4 \%$ (95\% CI: $16.0-16.8 \%$ ). The risk in men was $23.3 \%$ (95\% CI: $22.6-24.0 \%)$ and in women was $11.6 \%$ (95\% CI: $11.3-12.0 \%$ ) ( $P<0.001)$. In addition, $47.8 \%$ (95\% CI: $45.4-50.2 \%$ ) of the men and $14.9 \%$ (95\% CI: $13.5^{-}$ $16.3 \%$ ) of the women had a high CVD risk (>20\%). Mean CVD risk and prevalence of high CVD risk according to age and sex are shown in Table 1 . The relationship between the age and risk of CVD is also shown in Figure 1. It shows that the risk of CVD increased with age in both men and women, but the increase was greater in men. 
Age, diabetes, hypertension, waist circumference, total cholesterol and HDL cholesterol levels were significantly associated with CVD risk in both men and women (Table 2). Smoking and BMI $\geq 40 \mathrm{~kg} / \mathrm{m}^{2}$ were also associated with CVD risk in men, while triglyceride level was also associated with CVD risk in women. Generating elasticities for the coefficients in Table 2 showed that diabetes and hypertension increased the CVD risk by $7.6 \%$ and $5.6 \%$ in women and $11.7 \%$ and $7.7 \%$ in men. Smoking was also an important risk factor which increased the CVD risk by $7.4 \%$ in men. Smoking increased the CVD risk by 3.0\% in women but this was not statically significant $(P=0.059)$. Each $1 \%$ increase in HDL cholesterol, decreased the CVD risk by $0.48 \%$ and $0.17 \%$ in men and women, respectively. Each $1 \%$ increase in age, waist circumference, total cholesterol and triglycerides increased the CVD risk in women by $0.52 \%, 0.05 \%, 0.06 \%$ and $0.005 \%$, respectively. For men these rates were $1.0 \%$, $0.05 \%$, and $0.11 \%$ for age, waist circumference and total cholesterol, respectively. The CVD risk decreased by $4.4 \%$ in men with a BMI $\geq 40 \mathrm{~kg} / \mathrm{m}^{2}(P=0.18)$, while no significant association between BMI and CVD risk was seen in women.

The relationship of BMI with CVD risk, total cholesterol and triglycerides is shown in Figure 2. In both sexes, higher BMI was associated with an increase in CVD risk. However, this increase was linear in women and quadratic in men; that is, in men, the risk plateaued at BMI $35 \mathrm{~kg} / \mathrm{m}^{2}$ and more and even decreased with further increases in BMI (BMI paradox). The associations of total cholesterol and triglycerides with BMI were also different in men and women. In men, this association had a reverse $\mathrm{U}$ shape (Figure 2).

\section{Discussion}

Our results showed that the risk of CVD is high in people aged 45-69 years old in Shahroud. The mean risk was $23.3 \%$ and $11.6 \%$ in men and in women, respectively; and $47.8 \%$ of men and $14.9 \%$ of women had a CVD risk $>20 \%$. This emphasizes the need for rapid implementation of treatment and preventive interventions. Similar studies in the Islamic Republic of Iran have reported lower risk in both males and females $(11,13,15)$. However in a longitudinal study in the country with a 10-year follow-up of people aged 40-75 years, a high incidence of CVD $(21.0 \%$ in men and $12.0 \%$ in women) was reported (20). Another study found that $46.5 \%$ of Iranians were eligible for statin therapy according to the ACC/AHA guideline (21). Our prevalence of high CVD risk $(28.3 \%)$ is slightly higher than recent research in Malaysia (20.5\%) (22), Australia (19.9\%) (23) and the United States of America (22.6\% in hypertensive patients) (24). The laboratory-based mean 10-year risk of fatal and non-fatal CVD in Iranian people aged 40-64 years was $11.2 \%$ in men and $9.0 \%$ in women, which similar to Cambodia and were the highest risk of 10 countries with recent national health surveys (25). Differences in age groups, race and ethnicity of participants, and different methods for estimating CVD risk are important fac-

\begin{tabular}{|c|c|c|}
\hline Age groups (years) by sex & Mean CVD risk \% $(95 \% \mathrm{CI})$ & Prevalence $(95 \% \mathrm{CI})$ of high CVD risk (> 20\%) \\
\hline \multicolumn{3}{|l|}{ Male } \\
\hline $45-49$ & $14.1(13.0-15.1)$ & $19.3(14.9-23.7)$ \\
\hline $50-54$ & $17.5(16.5-18.4)$ & $28.7(24.6-32.9)$ \\
\hline $55-59$ & $23.5(22.3-24.7)$ & $49.5(45.2-53.8)$ \\
\hline $60-64$ & $29.5(28.0-31.0)$ & $68.1(63.5-72.7)$ \\
\hline $65-69$ & $35.7(33.6-37.9)$ & $83.8(79.1-88.5)$ \\
\hline Total & $23.3(22.6-24.0)$ & $47.8(45.3-50.2)$ \\
\hline \multicolumn{3}{|l|}{ Female } \\
\hline $45-49$ & $5.9(5.6-6.2)$ & $1.0(0.2-1.9)$ \\
\hline $50-54$ & $8.9(8.4-9.4)$ & $7.0(5.2-8.7)$ \\
\hline $55-59$ & $12.8(12.1-13.6)$ & $16.2(13.4-18.9)$ \\
\hline $60-64$ & $15.7(14.9-16.6)$ & $26.1(22.1-30.1)$ \\
\hline $65-69$ & $21.2(19.5-22.9)$ & $43.4(37.4-49.4)$ \\
\hline Total & $11.6(11.3-12.0)$ & $14.9(13.5-16.3)$ \\
\hline \multicolumn{3}{|l|}{ Total sample } \\
\hline $45-49$ & $8.6(8.1-9.1)$ & $7.0(5.3-8.6)$ \\
\hline $50-54$ & $12.3(11.8-12.8)$ & $15.6(13.5-17.6)$ \\
\hline $55-59$ & $17.4(16.6-18.1)$ & $30.4(27.7-33.1)$ \\
\hline $60-64$ & $22.0(21.1-23.0)$ & $45.3(42.1-48.5)$ \\
\hline $65-69$ & $27.9(26.4-29.4)$ & $62.1(57.8-66.3)$ \\
\hline Total & $16.4(16.0-16.8)$ & $28.3(27.1-29.6)$ \\
\hline
\end{tabular}

CI: confidence interval. 


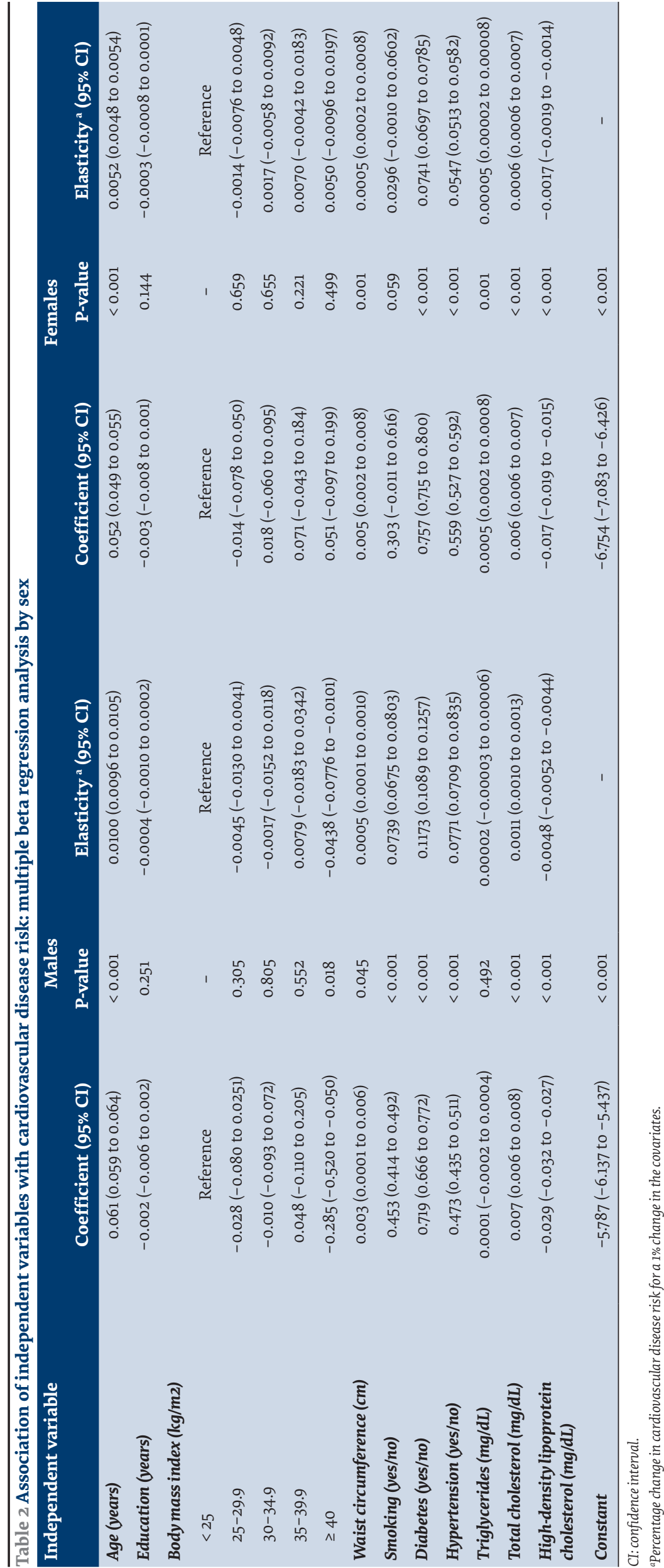

tors to consider when comparing CVD risk in above-mentioned studies.

In our study, the risk of CVD in women was considerably higher than in many studies $(11,13,14,22,26,27)$. Only one American study had a similar prevalence of high CVD risk as our study: prevalence of CVD risk $>20 \%$ was $15.0 \%$ (24) while ours was $14.9 \%$. It should be noted that some researchers concluded that CVD risk in women is overestimated if using the Framingham risk score (8). Similar to other studies, CVD risk was higher in men than women, and increased with age in both sexes $(7,11,13,26,27)$. One of the important points of our results was the interaction between age and sex; increased CVD risk with age was higher in men than women. Men had a higher rate of increase in CVD risk from the age of 55 years onwards, indicating the presence of more risk factors in men in middle age and early old age than women of the same age. Therefore, more attention should be paid to developing prevention and treatment interventions for men.

There was also interaction between BMI and sex for CVD risk. Increasing BMI up to $35 \mathrm{~kg} / \mathrm{m}^{2}$ was associated with higher CVD risk in men than in women. However, in men, the risk decreased with further increase in BMI (BMI paradox). This finding is difficult to explain and requires further investigation. A possible explanation may be differences in the type of obesity (abdominal versus nonabdominal) in men with BMI over $35 \mathrm{~kg} /$ $\mathrm{m}^{2}$ or better lifestyle (i.e. healthier eating, more physical activity and less smoking) in this obese group. Some studies have shown that changes in low-density lipoprotein cholesterol and triglycerides with an increase in BMI are not the same in men and women (28). In our study, BMI above $33 \mathrm{~kg} / \mathrm{m}^{2}$ in men was associated with a reduction in total cholesterol and triglycerides, while this was not the case for women. A possible explanation may be that obese men comply more with use of lipid-lowering drugs when they reach a high level of obesity. An Iranian study in 2012 reported that the prevalence of metabolic syndrome (which is directly related to the risk of CVD) and those with medium risk for CVD decreased in men with a BMI of $\geq 40 \mathrm{~kg} / \mathrm{m}^{2}$, while it increased linearly in women (29). In a large cohort study in the Islamic 


\section{Figure 1 Association of age and cardiovascular risk by sex}

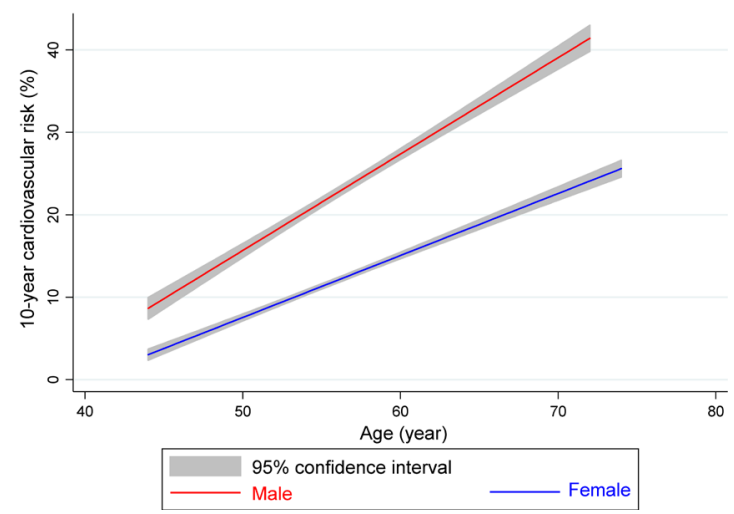

Republic of Iran, BMI was not associated with CVD mortality in men and was inversely associated with CVD mortality in women (30). In addition, a cross-sectional study of office workers with limited sample size did not find any association between CVD risk (predicted by the Framingham risk score) and BMI level (15). Furthermore, a study with an international cohort showed that CVD risk in obese and overweight people was not higher than those with normal BMI, and a reverse J-shaped curve persisted between BMI category and incidence of CVD outcomes (31). A longitudinal study in the United States showed that BMI had little independent influence (0.07\% per $1 \mathrm{~kg} / \mathrm{m}^{2}$ increase) on 10-year atherosclerotic CVD risk scores (32). A systematic review of 40 cohort studies found that overweight and obese people had better survival and lower CVD events (33). The above-mentioned studies (3133) highlight that BMI is not a good proxy for body fat.

As expected, having diabetes, smoking and having high blood pressure were associated with higher risk of CVD. Other studies also have reported the same $(7,8,24,34,35)$. Of these three risk factors, diabetes is associated with the greatest risk of CVD. In our study, low levels of HDL cholesterol increased the risk of CVD more significantly than high levels of total cholesterol and triglycerides.

The main strengths of our study are its study design, large sample size and accuracy of measurements of the variables, including blood pressure, height, weight and laboratory measures. However, our study has some limitations. The risks calculated in the study are based on the Framingham model, which was assumed to be applicable to the Islamic Republic of Iran. However, the Framingham risk score has been reported to be the most useful risk assessment tool in Asian countries such as India (36). As ours was a cross-sectional study, the associations found between the variables examined and CVD cannot be considered causal. In the next phases of the Shahroud Eye Cohort Study, it will be possible to assess more accurately the risk of CVD.

Shahroud can be considered a typical city in the Islamic Republic of Iran with population and health indices about average for the country. Therefore, our
Figure 2 Association of body mass index and cardiovascular risk (A), total cholesterol (B) and triglycerides (C) by sex
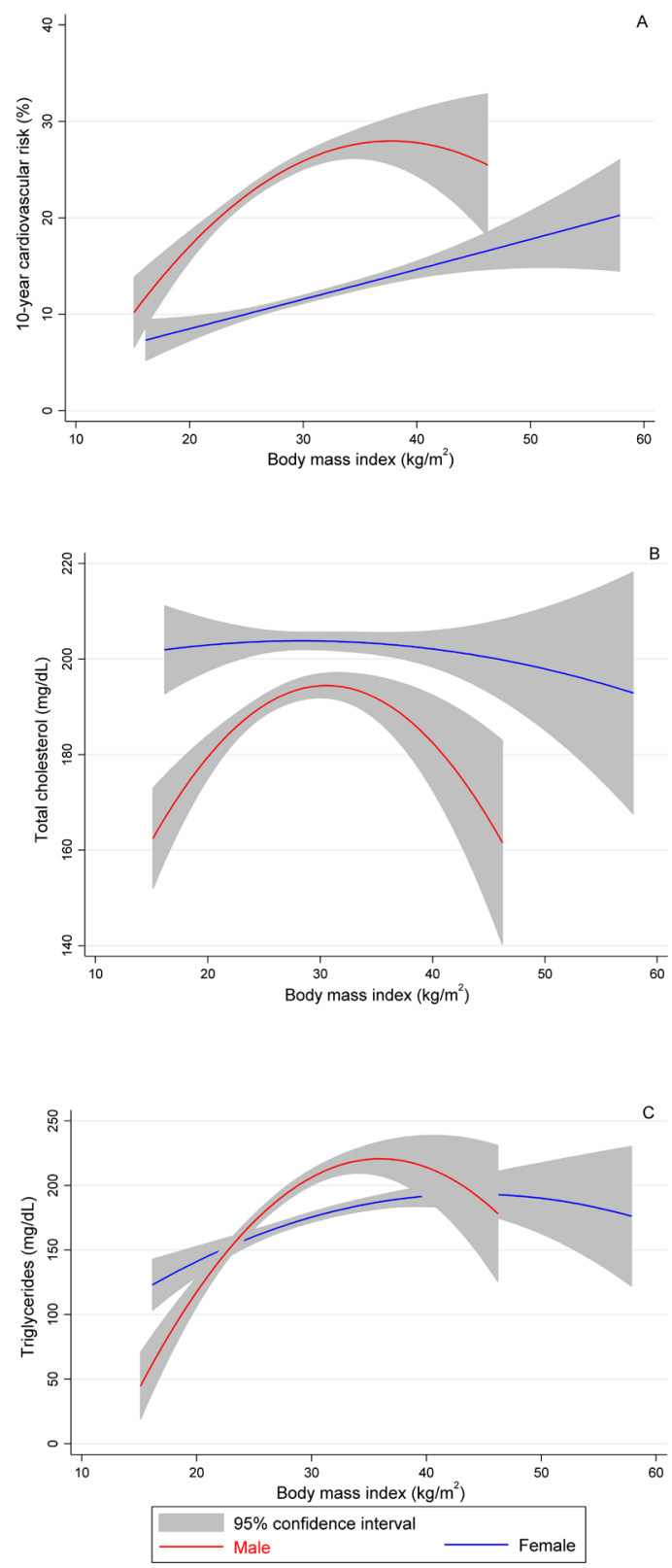

results show that the 10-year risk of incident CVD is high in the middle-aged and elderly Iranian population in urban areas. Our findings may be useful for policymaking and highlight the need for a concerted effort to provide effective interventions to reduce CVDs in the country.

Funding: The Shahroud Eye Cohort Study was supported by the Noor Ophthalmology Research Center and Shahroud University of Medical Sciences (Grant Number 8737). Our study did not receive any specific grant from funding agencies in the public, commercial or not-forprofit sectors.

Competing interests: None declared. 


\section{Prédiction du risque de maladie cardio-vasculaire sur une période de 10 ans en République islamique d'Iran, et paradoxe de l'indice de masse corporelle Résumé}

Contexte: L'évaluation du risque de maladie cardio-vasculaire est essentielle pour la prévention des maladies dans chaque région.

Objectifs : La présente étude visait à étudier le risque de maladie cardio-vasculaire sur 10 ans et ses déterminants dans une population adulte à Shahroud, en République islamique d'Iran.

Méthodes : Au total, 4737 personnes âgées de 45 à 69 ans ont été évaluées. Le risque de maladie cardio-vasculaire sur 10 ans a été calculé à l'aide de la méthode de notation du risque de Framingham. Le risque de maladie cardio-vasculaire est indiqué en pourcentage du risque et en intervalles de confiance (IC) à $95 \%$. Les facteurs affectant le risque de maladie cardio-vasculaire ont été évalués au moyen d'une analyse de régression multiple bêta .

Résultats : L'âge moyen des participants était de 55,9 ans ; $41 \%$ étaient des hommes. Le risque moyen de développer une maladie cardio-vasculaire sur 10 ans était de 16,4 \% (IC à $95 \%$ : 16,0-16,8 \%) ; 28,3\% des participants avaient un risque de plus de $20 \%$ (47,8 \% des hommes et 14,9\% des femmes). L'âge, le diabète, le tabagisme (uniquement chez les hommes), l'hypertension artérielle, les triglycérides (uniquement chez les femmes), le tour de taille, le cholestérol total et le cholestérol des lipoprotéines de haute densité étaient associés de manière significative au risque de maladie cardiovasculaire. Chez les hommes, on a constaté une augmentation non significative du risque avec un indice de masse corporelle plus élevé pouvant atteindre $39,9 \mathrm{~kg} / \mathrm{m}^{2}$; cependant, le risque diminuait de 4,4\% lorsque l'indice de masse corporelle était supérieur ou égal à $40 \mathrm{~kg} / \mathrm{m}^{2}(p=0,18)$.

Conclusions: Le risque de maladie cardio-vasculaire était très élevé, surtout chez les hommes. Des interventions efficaces devraient être mises en œuvre pour réduire les facteurs de risque des maladies cardio-vasculaires. Des études longitudinales sont recommandées pour étudier l'effet de l'indice de masse corporelle sur le risque de maladie cardiovasculaire.

$$
\begin{aligned}
& \text { توقُع خطر الإصابة بأمراض القلب والأوعية الدموية لمدة · 1 سنوات في شاهرود بجمهورية إيران الإسامية ومتناقضة منسب كتلة } \\
& \text { محمدحسن اماميان، حسن هاشمي، أكبر فتوحي } \\
& \text { الخالاصة } \\
& \text { الخلفية: يُعد تقييم خطر الإصابة بأمر اض القلب والأوعية الدموية أمراً اضرورياً للوقاية من الأمراض في جميع المناطق. }
\end{aligned}
$$

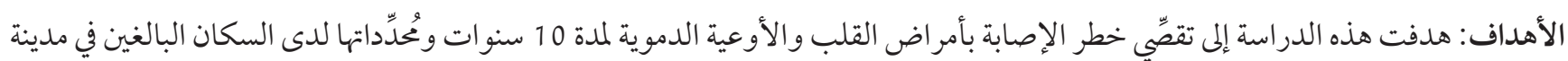

$$
\begin{aligned}
& \text { شاهرود بجمهورية إيران الإسلامية. مدهدئ. }
\end{aligned}
$$

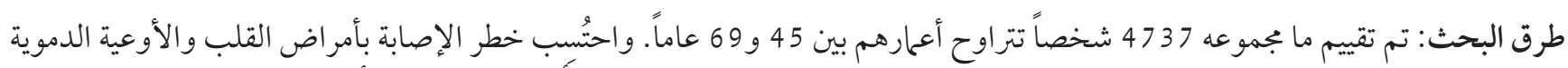

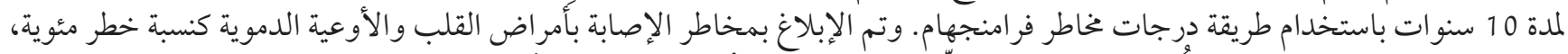

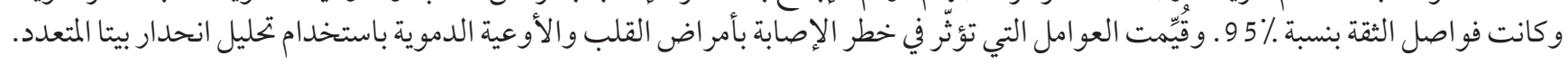

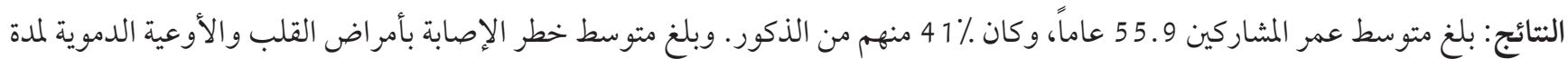

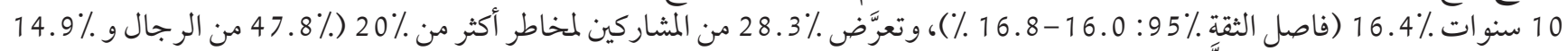

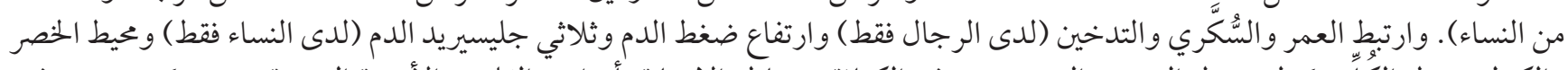

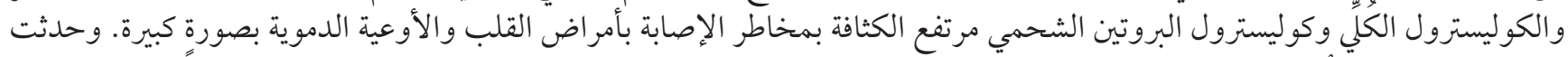

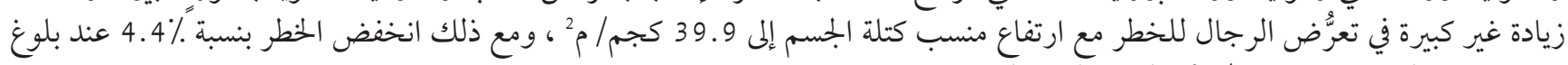

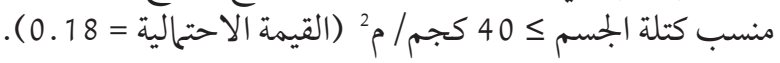




\section{References}

1. Roth GA, Johnson C, Abajobir A, Abd-Allah F, Abera SF, Abyu G, et al. Global, regional, and national burden of cardiovascular diseases for 10 causes, 1990 to 2015. J Am Coll Cardiol. 2017;70(1):1-25. https://doi.org/10.1016/j.jacc.2017.04.052

2. Cardiovascular diseases (CVDs). Fact sheet. Geneva: World Health Organization; 2017 (http://www.who.int/mediacentre/factsheets/fs317/en/, accesssed 29 March 2019).

3. GBD 2017 Causes of Death Collaborators, Global, regional, and national age-sex-specific mortality for 282 causes of death in 195 countries and territories, 1980-2017: a systematic analysis for the Global Burden of Disease Study 2017. Lancet. 2018;392(10159):1736-88. https://doi.org/10.1016/S0140-6736(18)32203-7

4. Fahimfar N, Khalili D, Sepanlou SG, Malekzadeh R, Azizi F, Mansournia MA, et al. Cardiovascular mortality in a Western Asian country: results from the Iran Cohort Consortium. BMJ Open. 2018;8(7):e020303. https://doi.org/10.1136/bmjopen-2017-020303

5. Sadeghi M, Haghdoost AA, Bahrampour A, Dehghani M. Modeling the burden of cardiovascular diseases in Iran from 2005 to 2025: the impact of demographic changes. Iran J Public Health. 2017;46(4):506-16.

6. Lloyd-Jones DM. Cardiovascular risk prediction: basic concepts, current status, and future directions. Circulation. 2010;121(15):1768-77. https://doi.org/10.1161/CIRCULATIONAHA.109.849166

7. Bozorgmanesh M, Hadaegh F, Azizi F. Predictive accuracy of the "Framingham's general CVD algorithm" in a Middle Eastern population: Tehran Lipid and Glucose Study. Int J Clin Pract. 2011;65(3):264-73. https://doi.org/10.1111/j.1742-1241.2010.02529.x

8. Chia YC, Gray SY, Ching SM, Lim HM, Chinna K. Validation of the Framingham general cardiovascular risk score in a multiethnic Asian population: a retrospective cohort study. BMJ Open. 2015;5(5):e007324. https://doi.org/10.1136/bmjopen-2014-007324

9. Selvarajah S, Kaur G, Haniff J, Cheong KC, Hiong TG, van der Graaf Y, et al. Comparison of the Framingham Risk Score, SCORE and WHO/ISH cardiovascular risk prediction models in an Asian population. Int J Cardiol. 2014;176(1):211-8. https://doi. org/10.1016/j.ijcard.2014.07.066

10. Gander J, Sui X, Hazlett LJ, Cai B, Hebert JR, Blair SN. Factors related to coronary heart disease risk among men: validation of the Framingham Risk Score. Prev Chronic Dis. 2014;11:E140. https://doi.org/10.5888/pcd11.140045

11. Motamed N, Mardanshahi A, Saravi BM, Siamian H, Maadi M, Zamani F. The 10-year absolute risk of cardiovascular (CV) events in Northern Iran: a population based study. Mater Sociomed. 2015;27(3):158-62. https://doi.org/10.5455/msm.2015.27.158-162

12. Yousefzadeh G, Shokoohi M, Najafipour H, Shadkamfarokhi M. Applying the Framingham risk score for prediction of metabolic syndrome: the Kerman Coronary Artery Disease Risk Study, Iran. ARYA Atheroscler. 2015;11(3):179-85.

13. Ghayour-Mobarhan M, Moohebati M, Esmaily H, Ebrahimi M, Parizadeh SMR, Heidari-Bakavoli AR, et al. Mashhad stroke and heart atherosclerotic disorder (MASHAD) study: design, baseline characteristics and 10-year cardiovascular risk estimation. Int J Public Health. 2015;60(5):561-72. https://doi.org/10.1007/s00038-015-0679-6

14. Motamed N, Rabiee B, Perumal D, Poustchi H, Miresmail SJ, Farahani B, et al. Comparison of cardiovascular risk assessment tools and their guidelines in evaluation of 10-year CVD risk and preventive recommendations: a population based study. Int J Cardiol. 2017;228:52-7. https://doi.org/10.1016/j.ijcard.2016.11.048

15. Nakhaie MR, Koor BE, Salehi SO, Karimpour F. Prediction of cardiovascular disease risk using Framingham risk score among office workers, Iran, 2017. Saudi J Kidney Dis Transpl. 2018;29(3):608-14. https://doi.org/10.4103/1319-2442.235179

16. Sarrafzadegan N, Hassannejad R, Marateb HR, Talaei M, Sadeghi M, Roohafza HR, et al. PARS risk charts: a 10-year study of risk assessment for cardiovascular diseases in Eastern Mediterranean Region. PLoS One. 2017;12(12):e0189389. https://doi.org/10.1371/ journal.pone.0189389

17. Hajian-Tilaki K, Heidari B. Comparison of abdominal obesity measures in predicting of 10-year cardiovascular risk in an Iranian adult population using ACC/AHA risk model: A population-based cross-sectional study. Diabetes Metab Syndr. 2018;12(6):991-7. https://doi.org/10.1016/j.dsx.2018.06.012

18. Fotouhi A, Hashemi H, Shariati M, Emamian MH, Yazdani K, Jafarzadehpur E, et al. Cohort profile: Shahroud Eye Cohort Study. Int J Epidemiol. 2013;42(5):1300-8. https://doi.org/10.1093/ije/dys161

19. D’Agostino RB Sr, Vasan RS, Pencina MJ, Wolf PA, Cobain M, Massaro JM, et al. General cardiovascular risk profile for use in primary care: the Framingham Heart Study. Circulation. 2008;117(6):743-53. https://doi.org/10.1161/CIRCULATIONAHA.107.699579

20. Khalili D, Asgari S, Hadaegh F, Steyerberg EW, Rahimi K, Fahimfar N, et al. A new approach to test validity and clinical usefulness of the 2013 ACC/AHA guideline on statin therapy: a population-based study. Int J Cardiol. 2015;184:587-94. https://doi. org/10.1016/j.ijcard.2015.03.067

21. Asgari S, Abdi H, Hezaveh AM, Moghisi A, Etemad K, Beni HR, et al. The burden of statin therapy based on ACC/AHA and NCEP ATP-III guidelines: an Iranian survey of non-communicable diseases risk factors. Sci Rep. 2018;8(1):4928. https://doi.org/10.1038/ S41598-018-23364-9

22. Su TT, Amiri M, Mohd Hairi F, Thangiah N, Bulgiba A, Majid HA. Prediction of cardiovascular disease risk among low-income urban dwellers in metropolitan Kuala Lumpur, Malaysia. Biomed Res Int. 2015;2015:516984. https://doi.org/10.1155/2015/516984

23. Banks E, Crouch SR, Korda RJ, Stavreski B, Page K, Thurber KA, et al. Absolute risk of cardiovascular disease events, and blood pressure- and lipid-lowering therapy in Australia. Med J Aust. 2016;204(8):320. https://doi.org/10.5694/mja15.01004

24. Wong ND, Dede J, Chow VH, Wong KS, Franklin SS. Global cardiovascular risk associated with hypertension and extent of treatment and control according to risk group. Am J Hypertens. 2012;25(5):561-7. https://doi.org/10.1038/ajh.2012.2 
25. Ueda P, Woodward M, Lu Y, Hajifathalian K, Al-Wotayan R, Aguilar-Salinas CA, et al. Laboratory-based and office-based risk scores and charts to predict 10-year risk of cardiovascular disease in 182 countries: a pooled analysis of prospective cohorts and health surveys. Lancet Diabetes Endocrinol. 2017;5(3):196-213. https://doi.org/10.1016/S2213-8587(17)30015-3

26. Gray BJ, Bracken RM, Turner D, Morgan K, Mellalieu SD, Thomas M, et al. Predicted 10-year risk of cardiovascular disease is influenced by the risk equation adopted: A cross-sectional analysis. Br J Gen Pract. 2014;64(627):e634-e40. https://doi.org/10.3399/ bjgp14X681805

27. Yang Q, Zhong Y, Ritchey M, Loustalot F, Hong Y, Merritt R, et al. Predicted 10-year risk of developing cardiovascular disease at the state level in the U.S. Am J Prev Med. 2015;48(1):58-69. https://doi.org/10.1016/j.amepre.2014.09.014

28. Hu FB, Wang B, Chen C, Jin Y, Yang J, Stampfer MJ, et al. Body mass index and cardiovascular risk factors in a rural Chinese population. Am J Epidemiol. 2000;151(1):88-97. https://doi.org/10.1093/oxfordjournals.aje.a010127

29. Khosravi A, Akhavan Tabib A, Golshadi I, Dana Siadat Z, Bahonar A, Zarfeshani S, et al. The relationship between weight and CVD risk factors in a sample population from central Iran (based on IHHP). ARYA Atheroscler. 2012;8(2):82-9.

30. Sepanlou SG, Malekzadeh R, Poustchi H, Sharafkhah M, Ghodsi S, Malekzadeh F, et al. The clinical performance of an office-based risk scoring system for fatal cardiovascular diseases in north-east of Iran. PLoS One. 2015;10(5):e0126779. https://doi. org/10.1371/journal.pone.0126779

31. Hansel B, Roussel R, Elbez Y, Marre M, Krempf M, Ikeda Y, et al. Cardiovascular risk in relation to body mass index and use of evidence-based preventive medications in patients with or at risk of atherothrombosis. Eur Heart J. 2015;36(40):2716-28. https:// doi.org/10.1093/eurheartj/ehv347

32. Appiah D, Schreiner PJ, Durant RW, Kiefe CI, Loria C, Lewis CE, et al. Relation of longitudinal changes in body mass index with atherosclerotic cardiovascular disease risk scores in middle-aged black and white adults: the Coronary Artery Risk Development in Young Adults (CARDIA) Study. Ann Epidemiol. 2016;26(8):521-6. https://doi.org/10.1016/j.annepidem.2016.06.008

33. Romero-Corral A, Montori VM, Somers VK, Korinek J, Thomas RJ, Allison TG, et al. Association of bodyweight with total mortality and with cardiovascular events in coronary artery disease: a systematic review of cohort studies. Lancet. 2006;368(9536):66678. https://doi.org/10.1016/S0140-6736(06)69251-9

34. D’Agostino RB Sr, Pencina MJ, Massaro JM, Coady S. Cardiovascular disease risk assessment: insights from Framingham. Glob Heart. 2013;8(1):11-23. https://doi.org/10.1016/j.gheart.2013.01.001

35. Singh SK, Pant B, Davey A, Shukla A, Ahmad S. Dyslipidaemia \& Framingham risk score: tools for prediction of cardiovascular diseases as public health problem. Indian J Comm Health. 2016;28(1):45-50.

36. Garg N, Muduli SK, Kapoor A, Tewari S, Kumar S, Khanna R, et al. Comparison of different cardiovascular risk score calculators for cardiovascular risk prediction and guideline recommended statin uses. Indian Heart J. 2017;69(4):458-63. https://doi. org/10.1016/j.ihj.2017.01.015 